\title{
Planes, Walls, and Bits of Sound: Healing a Voice
}

\author{
ZEYNEP BULUT
}

\section{Introduction}

The use of non-linguistic voice in 20th century European avant-garde and American experimental music manifests various acoustic affinities between the so-called "normal" and "abnormal" speech. What do the acoustic similarities between the "aestheticized" and the "pathologized" forms of speech tell us about the affective knowledge of the hearing body and voice? Is it possible to consider the voice in avantgarde and experimental music a medium to unsettle and expand on the knowledge of the voice, language and speech constituted by the $20^{\text {th }}$ century history of speech pathology? This article intends to explore these questions.

Speech pathology evolves through physiological, mental and developmental, linguistic and cultural turns. The early 20 th century included cases of articulation and stuttering, which led to the exploration of the vocal production of speech sounds in auditory segmentation and especially phonemes as atomic units of speech. ${ }^{1}$ Towards the mid century, neurological cases such as aphasia created the urge for conceptual and empirical distinctions between speech and language. Neurologist and psychiatrist Kurt Goldstein introduced the notion of inner language, which was primarily based on Gestalt psychology, and which indicated a layer of mental processing of sounds and symbol formation. ${ }^{2}$ Goldstein's notion of inner language and "organismic theory" ${ }^{3}$ articulated the relation between the whole body and its physical and social environment in speech production and perception. In the 60s, studies on language learning were mostly influenced by linguistics such as Noam Chomsky's theory of generative and transformational grammar. The emphasis on formal rules and models of language heightened the distinct categorizations of syntax, semantics, and phonology. Since the 70s, speech perception and language learning have been revisited in more functional terms, highlighting the culturally and socially communicative aspects of speech, language and voice. Throughout, speech perception and language learning have also been informed by technologies of speech recognition and synthesis.

\footnotetext{
${ }^{1}$ See Samuel Potter's Speech and its Defects (1882) and Edward Wheeler Scripture's, Stuttering and Lisping (1912). Another significant figure in this period was Charles Van Riper. Van Riper's book, Speech Correction: Principles and Methods (1939), also indicated the role of physical environment and social context in diagnosing and treating physiological dysfunctions of speech. Samuel Potter, Speech and its Defects (Philadelphia, PA: P. Blakiston, Son \& Co., 1882); Edward Wheeler Scripture, Stuttering and Lisping (NY: The Macmillan Co., 1912); Charles Van Riper, Speech Correction: Principles and Methods (New York: Prentice-Hall Inc., 1939). Also see Emeritus Professor Judith Felson Duchan's homepage on history of speech-language pathology. https://www.acsu.buffalo.edu/ duchan/index.html. This article is based on the chapter, "Primary Bodily Contact: The Sound Envelope in Lucier's I am Sitting in a Room," included in my dissertation, "La Voix-Peau: Understanding the Physical, Phenomenal and Imaginary Limits of the Human Voice Through Contemporary Music," (Ph.D. diss., University of California, San Diego, 2011).

${ }^{2}$ Kurt Goldstein, Language Disturbances: Aphasic symptom complexes and their significance for medicine and theory of language (New York: Grune \& Stratton, 1948).

${ }^{3}$ See Kurt Goldstein (1937), The Organism: A holistic approach to biology derived from pathological data in man, with a foreword by Oliver Sacks (New York: Zone Books, 1995).
} 
One can read this history of speech pathology-its theoretical and empirical tendencies and diagnostic and therapeutic methods-in line with the non-linguistic voice in avant-garde and experimental music history, in line with what I call "skin-voice" - that is, voice as embodied sound, as a physical and phenomenal matrix of senses, a point of contact and difference between self and the external world. This use helps us read the historical turns of speech pathology in a different light. The connection between the history of speech pathology and the non-linguistic voice is not only reinforced by various movements in experimental music_Dada sound poetry, Artaud's physical theatre, 60s' experimentalism, interdisciplinary performance network and conceptions of sound-but also the personal narratives of composer and artists. ${ }^{4}$

Take Lucier's I am sitting in a room (1970). A stutterer himself, Lucier reads a text, records his speaking — stuttering — voice, plays it back into the room, and re- records the playback until the text and his speaking voice dissolves into the room frequencies. He posits the piece as an activity to "smooth out any speech irregularities that he might have." Another example is theatre director Robert Wilson's use of language and speech in the landmark opera, Einstein on the Beach (1974), which was largely inspired by the writings and autism of Christopher Knowles. Wilson also had mild speech impairment and worked as a therapist. In this chapter, I will focus on Lucier's I am sitting in a room and suggest a cross reading of the piece with cases of autism, in particular with cases of verbal and psychic deafness.

My intention is not to discuss the piece as a form of functional treatment so as to normalize or neutralize the irregularity. Quite the contrary, I wish to contest the "normalcy" of speech regularity. Looking at $I$ am sitting in a room through verbal and psychic deafness (and vice versa), the goal is to examine the matter and atmosphere of sound in constructing and expressing a voice before and beyond words, and more significantly, to expand on what could speak otherwise and how, not as pathology but as a mode of speech which is not limited to verbal language.

\section{I am sitting in a room}

I am sitting in a room, different from the one you are in now. I am recording the sound of my speaking voice and I am going to play it back into the room again and again until the resonant frequencies of the room reinforce themselves so that any semblance of my speech, with perhaps the exception of rhythm, is destroyed. What you will hear, then, are the natural resonant frequencies of the room articulated by speech. I regard this activity not so much as a demonstration of a physical fact, but more as a way to smooth out any irregularities my speech might have. ${ }^{6}$

So begins Alvin Lucier's famous work, I am sitting in a room. In the approximately 40 minute piece, Lucier, who stutters, reads and plays 32 iterations of this text in the room. Between each iteration, there is pause. Throughout the first third of the iterations, the text is intelligible. Toward the second third of the piece, Lucier's speaking voice begins to melt into melodic patterns. One begins to hear the speech melody underneath the words. In the last third of the piece, the speech melody gradually dominates the words whereby the phonemes_and especially the fricative consonants—become rhythmic punctuations, and the

\footnotetext{
${ }^{4} \mathrm{~A}$ cross reading between clinical cases/psychopathologies and aesthetic forms is worthwhile, as such reading manifests how both "pathologized" and "aestheticized" voices might deconstruct verbal language as a system, and imagine and articulate sound as a form of speaking body. Christopher Eagle suggests a similar cross reading in literary studies. Christopher Eagle, Talking Normal: Literature, Speech Disorders, and Disability, edited by Christopher Eagle (New York: Routledge, 2014).

${ }^{5}$ Alvin Lucier, I am sitting in a room (New York: Lovely Music, 1990).

${ }^{6}$ Ibid.
} 
pauses between the iterations turn into louder echoes of one another. While the listener is familiarized with the text during the first third of the piece, the dissolution of the speaking voice leads to the dissolution of the text as well. In the course of such decompression, speech melodies change into pitched sounds, pitched sounds into continuous sound waves. Once the text vanishes, the verbal facet of the voice also disappears. What remains and what emerge after? I explore this question through the concepts of weight of speech, sonorous envelope, and intensity of sound. At the heart of this exploration, there is a stuttering voice, an irregularity of speech, and uncertain status of language.

\section{A stuttering voice: weight of speech, an uncertain language}

"I regard this activity not so much as a demonstration of a physical fact, but more as a way to smooth out any irregularities my speech might have," ${ }^{7}$ says Lucier. Following Lucier's cue and the spatial unfolding of the piece, a variety of writers, artists and scholars-Brandon La Belle, Seth Kim-Cohen and Steven Connor, to name a few-discuss "stutter" at the heart of I am sitting in a room. ${ }^{8}$ What kind of an irregularity is stutter? Stutter does not seem to be considered a severe pathology within the history of speech disorders. It is rather understood and treated as mild speech impediment, widely defined as a "developmental disorder of communication." In his recent book, Beyond Words, Steven Connor writes about stuttering. As he posits, throughout its history, "stammering has been regarded as the result of some material or physical, rather than spiritual case." This relates both to physiological dysfunctions of the body and to environmental matters, for instance the impact of the weather on the dryness and wetness of the tongue. ${ }^{11}$ Yet in its effect, Connor also reminds us of the fact that stuttering creates an urge for reflecting on the associations between the notion of vitality and affordances of the voice. The treatment of stuttering-both in the nineteenth and in the early twentieth-centuries-employs physical activities, tongue and drill exercises, which engage not simply with a training and disciplining of the voice, but also with a voice that is pushed further and forward to its outside. Extending-and also expanding-the physical capacity of the voice generates a surplus and lack at the same time, in Connor's words, a sense of "material fantasies, or phantasmal materialisms" 12 of the voice:

The voice is so saturated by the anxious dream of our 'life,' because it is itself one of the most important components of that will-to-life. The phantasm of the 'living voice' is the principal carrier of our hallucination of life. It is subject to a paradoxical vital economy. While drawing on the body for its force, and therefore subject to the vicissitudes of the body, it is nevertheless imagined to have the power to radiate new life back to the body from which emanates. But, as a surrogate or supplement, the voice is also itself in need of supplementation-hence the anxious regimes of voice cultivation, nurture, hygiene and healing which have multiplied since

\footnotetext{
${ }^{7}$ Ibid.

${ }^{8}$ See Brandon LaBelle, Background Noise: Perspectives on Sound Art (London, New York: Continuum, 2006/2010); Seth KimCohen, In the Blink of an Ear: Toward a Non-Cochlear Sonic Art (London, New York: Bloomsbury, 2009); Steven Connor, "Phonophobia: The Dumb Devil of Stammering," http://www.stevenconnor.com/phonophobia/.

${ }^{9}$ Richard Curlee, "Stuttering," in The MIT Encyclopedia of Communication Disorders, ed. Raymond D. Kent (Massachusetts: MIT Press, 2004), 220.

${ }^{10}$ Steven Connor, Beyond Words: Sobs, Hums, Stutters and other Vocalizations (London: Reaktion Books, 2014$), 18$.

${ }^{11}$ Connor looks at the histories of stuttering between the $15^{\text {th }}$ and the $20^{\text {th }}$ century. As he explains, the fifteenth century Italian physiognomist Bartolomeo della Rocca speculated "alcoholic vapour"—wine-as a cause of stammering. Following this argument, the $16^{\text {th }}$ century dealt with the "excessive dryness of tongue" resulting in stammering. Ibid., 18-20.

${ }^{12}$ Ibid.
} 
the end of the eighteenth century ${ }^{13}$

Lucier's stutter deals with this "phantasm of the living voice." Without necessarily training or cultivating the voice in a given way, without turning the voice into excess or a lack, it articulates_and also dissolves - the stutter within the room frequencies, within the immanent physical context. One can imagine this context as the simultaneous life and death of the recorded voice, as electronic space within which life and death simultaneously can take place. The liquidation of Lucier's stutter urges us to hear not only the dissolution of a particular voice into a physical space but also the process of the dissolution itself. The phenomenal end of $I$ am sitting in a room may then be the listener's body, not the speaker's. As it dissolves, the discursive weight of the speaking voice is translated into the intensity of the listening body. The external contact between the two bodies turns into a shared volume, depth, color, and amplitude. And the listener is carried away. What happens when we are carried away? Is gravity lost? Does our body become unsettled? If the dissolution of the external audio cavities leads to internal resonance, how can we identify the force of our experience?

The bridge between the second third and the last third of the piece crystallizes these questions. Here, the melodies begin to melt into continuous sounds, the countable rhythmic patterns become less decodable. The pause between the iterations_-breath—falls into a unified continuum of sounds in which dualities, such as the tangible phonemes of the text versus the intangible phrases of the text; the room resonance versus the speaking body; and the recorded voice versus the listening voice, vanish. At the core of this unfolding, the listener renews its skin, and embodies an anonymous, a weightless $I$ that is speaking. Recording plays an ironic role here. Even though recording seems to suggest the disembodiment of the voice, it leads us to engage with the physical transmission of the voice, to re-configure the embodiment of the voice.

With respect to such embodiment, consider Allen Weiss's thought-provoking piece, Breathless: Sound Recording, Disembodiment and The Transformation of Lyrical Nostalgia. ${ }^{14}$ Weiss reads examples from lyric poetry that later inspire sound poetry. Some of his highlights include Edgar Allan Poe's tales, Stephane Mallarme's poems and Antonin Artaud's physical theatre performances. ${ }^{15}$ Looking at these examples, Weiss discusses the fantasy of sound recording of the nineteenth century, and indicates the literary dialogues between dead voices, and that way, the equation of death with life. As he argues, the notion of sound recording is fed by the same idea of equating death with life, of establishing a "temporary eternity." 16 Similarly, in his book, The Audible Past, Jonathan Sterne shows the historical discourses and technologies behind making sound reproduction "more permanent" and the attempt to animate the "voices of the dead."17

Yet what do such re-animated voices do to another's voice, to the limits of imagining a speaking voice, and of speaking itself as one hears another? Allowing a surgical process of cutting the voice into pieces, recording technologies encourage encountering the plasticity of language along with the plasticity ${ }^{18}$

\footnotetext{
${ }^{13}$ Ibid. 17-18.

${ }^{14}$ Allen Weiss, Breathless: Sound Recording, Disembodiment, and the Transformation of Lyrical Nostalgia (Wesleyan: Wesleyan University Press, 2002).

${ }^{15}$ Ibid. xiii, 7.

${ }^{16}$ Ibid.

${ }^{17}$ Jonathan Sterne, The Audible Past: Cultural Origins of Sound Reproduction (Durham: Duke University Press, 2003$), 26$.

${ }^{18}$ My reading of the term, plasticity, refers to Catherine Malabou's notion of plasticity. In her article, "Plasticity and Elasticity in Freud's 'Beyond the Pleasure Principle," Malabou discusses plasticity as adaptation, as "the ability to cling to a form without getting destroyed by it." Catherine Malabou, "Plasticity and Elasticity in Freud's Beyond the Pleasure Principle," Diacritics 37 (2007): 84.
} 
of the voice. Radio artist and writer, Gregory Whitehead writes:

In the saturated buzz world of electronic media, our voices are inscribed with all kinds of "phonies," other than our own. The fact is, we cannot find our voice just by using it; we must be willing to cut it out of our throats, put it on the autopsy table, isolate and savor the various quirks and pathologies, then stitch it back together and see what happens ... The problem of the voice bodies (and the hunger to become entangled with other voice bodies) could resolve itself into the pure pleasure of speech in ruins ... ${ }^{19}$

Whitehead's beautiful telling of disintegrating the voice reinforces the flexibility and plasticity of the voice. But more significantly, the disintegration of the voice shows us how within the moments of cuts and the "pleasure of speech in ruins," we embrace the urge for hearing and being heard by another. The cuts of the voice ironically give a way to sonic continuum, a form of movement and force, which makes the meaningless "noises," the lost syllables of a voice audible and re-assembles them both as audible and as inaudible.

Similarly, I am sitting in a room pronounces the stutter not as a pathology to be rehabilitated but as a cut, an irregularity, a syncopation, which makes us hear how words disappear and reappear in our and other voices. We hear the commotion of the flesh as we disintegrate a syllable from a word. We reassemble the partial sound, the lost syllable, the sentence disembodied from its semantics. The disembodiment, loss, and inevitable re-embodiment of sound seem to be a particular one, that is negotiable and elastic, that cannot be pre-determined. We cannot fully objectify the lost sound. The playback of the recorded voice into the room more concretely underlines this acoustic process. The partial syllable cannot be brought back, unless it comes back on its own by accident in a particular moment. What we hear becomes more atmospheric. The transformation of the speech melody into continuous pitches help us concretely be in the air of the room, somewhat similar to Gaston Bachelard's notion of "aerial material imagination," ${ }^{20}$ that is the "poetic pluralities of breath." 21

\footnotetext{
${ }^{19}$ Gregory Whitehead is quoted in Steven Connor's article. See Steven Connor, “The Decomposing Voice of Postmodern Music," New Literary History 32 (2001): 480.

${ }^{20}$ In Air and Dreams, Gaston Bachelard qualifies "imagination" as "open and elusive." As opposed to "habituated" perception of things, Bachelard asserts the imagination as an opportunity to "human existence." Nevertheless, he does that by highlighting the matter of imagination, that is four physical elements of nature: air, water, earth and fire.

Accordingly, imagination is channeled through the "mobility of images" and direct "kinetic activity," which are not only limited to defined images. For Bachelard, the imaginary consists of infinite possibilities of physical and mental activity, and is embedded in reality. The lack of imagination indeed ends up deforming the reality function. "A person deprived of the function of the unreal is just as neurotic as the one deprived of reality function," he writes. The four elements here offer the possibility of material imagination, that is psyche's open perception of the matter -- the matter's own life -- and creative transformation of the matter into a metaphor. Bachelard asserts that "the physiology of the imagination obeys the law of the four elements," and reinforces this idea as such: "... a material element is the principle of a good conductor that gives continuity to the imagining psyche. In addition every element that the material imagination enthusiastically adopts prepares a special sublimation, a characteristic transcendence for the dynamic imagination."

Material imagination then becomes such a useful and inspiring concept to unfold the human voice, which is both a watery and an aerial projection of the being. Gaston Bachelard, Air and Dreams: An Essay on the Imagination of Movement, trans. Edith R. Farrell and C. Frederick Farrell (Dallas: The Dallas Institute of Humanities and Culture Publications, 1988), $1,2,4,6,7,8$.

${ }^{21}$ Weiss insightfully refers to Gaston Bachelard. He writes: "Poetry, like life, is a matter of breath, as Gaston Bachelard explains throughout L'air et les songes (Air and Dreams)." In the chapter oxymoronically entitled "La declamation muette" (Mute Declamation), he states: "The poetic breath, before being a metaphor, is a reality that can be found in the life of the poem, if one wishes to learn the lessons of the aerial material imagination. If more attention were placed on poetic exuberance, on all forms of the pleasure of speaking, softly, quickly, crying, murmuring, psalmodizing ... an incredible plurality of poetic breaths would be discovered." The poet is appropriately characterized by the famed definitions of the human being as a tuyau sonore (sonorous pipe) and a roseau pensant (thinking reed), such that even silence becomes a positive, meaningful function of breath..." Weiss, Breathless, 35, 36.
} 
In Edgar Allen Poe's story, The Facts in the Case of M. Valdemar, Valdemar, who is dying of pulmonary tuberculosis, tells his friend: "I am dead." 22 Weiss emphasizes this story and line to bring us back to the disembodiment of language, that is the uncertain state of life and death in language. I am dead assures neither death nor life. Both are possible, and equally not possible. Language creates an artificial existence of the two. The speaking voice, however, complicates this situation. As Weiss writes, we do not know whether Valdemar is alive or dead; all we know is that he speaks. ${ }^{23}$ This is the parallel that Weiss brilliantly draws with the recorded voice. Recorded voice seems to give rise to a similar effect for us. We do not precisely know who speaks; all we know is that somebody speaks. Where is speech in the equation of life and death? How far can speech be from language? To what extent does speech suggest life? To what extent does it assure death along with language? This is a philosophy of the flesh, where "the I, really is nobody, is the anonymous,' and where 'what there is to be grasped is a dispossession,"”24 writes Weiss.

To reiterate, the liquidation of Lucier's voice and stutter exposes this case of dispossession. Here the stutter can be considered the physical contact between the punctuated melodic phrases and the continuous pitched tones, between the speech sounds and the room resonance, and between the speaking body of the recorded voice and the listening body of the speaking voice. This dispossession of voice encourages an undoing of a given discourse of the text, a transcendence of the pre-carried weight of language, and allows an encounter with the audio cavities of the physical space.

The physical fit between sound and space suggests the spectrum of chance, the web of references, and the possibilities of movement, affect and change. ${ }^{25}$ The audio cavities-both linguistic and nonlinguistic fragments of Lucier's text and voice-take place on this spectrum. With the weightlessness of sound and the constant negotiation of breath, the physical contact becomes, as Lucier describes, a "fit" or a "natural selection of the frequencies, wave lengths" between the bodies in space. The embodiment of these frequencies (the contact) brings the idea of sonorous envelope, intensity and a vibrational ecology.

\section{Sonorous envelope, intensity, a vibrational ecology}

Voice in psychoanalysis is a controversial topic. Freud analyzes and employs voice-especially the non-verbal noises and breaks of voice and loss and irregularities of speech-as a positive "symptom" for accessing and revealing the unconscious, and as a portal_ "gateway" 26 - to knowing the self. Lacan, on the other hand, discusses voice-and again non-verbal gestures of the voice-not as an accountable or countable medium to know the self, but rather as a residue, a missing object, which makes this knowledge of the self almost impossible. Indeed it was only after Lacan himself suffered from aphasia that voice became a more central topic for him. Neither fully contained in language nor fully released by the body, Lacan then seems to formulate voice as a partial object, which belongs to the domain of desire, and which "cannot and must not fully speak." ${ }^{27}$ Psychoanalysis chases patterns and sequences of events that repeat and

\footnotetext{
${ }^{22}$ Ibid., 39, 40.

${ }^{23}$ Ibid.

${ }^{24}$ Weiss refers to Merleau-Ponty's two books, Phenomenology of Perception and Visible and Invisible. Here he quotes from Visible and Invisible. Ibid., 54. Maurice Merleau Ponty, Phenomenology of Perception, trans. Colin Smith (New York: Humanities Press, 1962); The Visible and the Invisible, trans. Alphonso Lingis (Evanston: Northwestern University Press, 1968).

${ }^{25}$ Here it would be worthwhile to indicate the use of the word, affect. The dispossession of the voice, and sounds, which do not belong to one particular body gestures Spinoza's—and later Deleuze and Guattari's—notion of affect. See also Sound Music Affect: Theorizing Sonic Experience, edited by Marie Thompson and Ian Biddle (London, New York: Continuum, 2013).

${ }^{26}$ Alice Lagaay, "Between Sound and Silence: Voice in the History of Psychoanalysis," E-pisteme, 1 (2008): 54, 55.

${ }^{27}$ Ibid., 57, 58.
} 
remain. It thus makes and narrates stories at the heart of a voice, which could appear more or less than itself.

Without a necessary engagement in narrativity, Anzieu's notion of ego-skin, however, highlights sensory registers, and in particular, focuses on sound as a global experience of senses. His theory allows considering voice a hybrid matter of internal sounds of the human body and concrete sounds of an external environment. Reformulating the Freudian ego as skin, as an interface between self and the external world, Anzieu draws attention to the physical and phenomenal constitutes of the Ego, of the sensory envelopes of skin, among which the sound envelope is primary. Sound and mother's voice have a peculiar function in the evolution of ego-skin, given that the human embryo is first enveloped by the mother's emission of bodily sounds, and that audio-phonic communication is one of the earliest channel for generating the baby's physical behavior and mental thought. ${ }^{28}$

The notion of envelope seems to suggest a degree of containment. I intend to use the notion of sound envelope not as a self-contained bubble, but as a layer or zone which requires a relation with its outside, with its other physical and social ecologies. In this context, I suggest considering Anzieu's sensory envelopes along with Daniel Stern's notion of "layered or emergent self." 29 It is of course true that Stern's notion of layered self does not prioritize any particular sensory register, but it emphasizes cross-modalities of senses. ${ }^{30}$ Despite its evolutionary foundation and developmental condition, I propose that Anzieu's analytical framework also attempts to articulate a relation, a cross modality, especially between phonemes and their placement and distribution in a physical environment.

Referring to French structural linguist Andre Mertinet, Anzieu reiterates phonemes as functional signifiers, which belong to "second articulation of language." 31 The phonemes operate as connective tissue between the baby's body and his physical environment. In the course of second articulation, around the first three months, "the maturation of fovea, the circular visio-motor reaction is established." 32 During this period, the baby begins to touch things that are relatively close and attempts to "reach toward the mother's voice" ${ }^{33}$ with the hand as a tangible thing. The physical process here informs the psychic development, preceding the Freudian Super-Ego that is learned by means of the "first articulation of language, the rules governing lexical usage, grammar and syntax." ${ }^{34}$ The constituents of the "second articulation," or the formants of the phonemes, come earlier and deliver a sensible surface, which on the one hand leads to the experience of an inner volume of the body, and which on the other hand provides an awareness of the

\footnotetext{
${ }^{28}$ Prior to his explanation of sound envelope as the primary layer of ego-skin, Anzieu guides us to British and American psychoanalytic literature to substantiate the conceptual necessity of the term. Three paradigms are addressed: Wilfred Bion's concept of the mother's breast as a psychic container of "space sensations (particularly cenesthetic and kinaesthetic)" and then a source of self's "representation, binding and introjection" ${ }^{28} ;$ H. Kohut's notion of "self's narcissistic fusion" with objects, that the self either mirrors itself in objects or idealizes the object itself; and lastly, Lacan's formulation of "mirror image of the whole unified body," and, in line with Lacan, Donald Winnicott's emphasis on the mother's face operating as the first mirror for the child. ${ }^{28}$ One common aspect of these paradigms is that they all tend to prioritize the visual aspects of the baby's physical experience. Anzieu contributes to this picture with his emphasis on "sound," as a global experience. Anzieu, The Skin-Ego, 157, 158, 163, 164.

${ }^{29}$ Daniel N. Stern, Forms of Vitality: Exploring Dynamic Experience in Psychology, the Arts, Psychotherapy, and Development (Oxford: Oxford University Press, 2010).

${ }^{30}$ See Erin Manning's discussion on Stern's “emergent and relational self” and cross-sensory modalities in her book Always More Than One. Erin Manning, "Towards a Leaky Sense of Self," Always More Than One: Individuation's Dance (Durham:

Duke University Press, 2013), 1-13.

${ }^{31}$ Anzieu., The Skin-Ego,164.

${ }^{32}$ Ibid.

${ }^{33}$ Ibid.

${ }^{34}$ Ibid., 167.
} 
outer environment while building an exterior boundary. Anzieu designates this double-sided flow as "sound-bath."

Consider I am sitting in a room a case of decompression of first articulation leading to the sensible surface of second articulation, a sound bath. In the 1970s, French psychiatrist Isi Beller founded a therapy, semiophony ("lexiphone therapy"), based on the idea of sound bath. ${ }^{35}$ Beller used this therapy for the children who suffer from aphasia and language disturbances. Generally speaking, aphasiac patients suffer from the difficulty of comprehending, producing and articulating the first articulation of language. They cannot translate sounds into a cohesive line of speech. To deal with this problem, the therapy first employs the absence of verbal language and speaking voice, where high-pitched harmonics, that can be sharp, loud, and possibly revealing the related overtones, are played. In this sonic ambience, the child is encouraged to engage a free association mode where $\mathrm{s} /$ he can draw, move around and play with the space without any necessary boundaries. Second, a "filtered" voice is played. Instead of free-floating harmonics, the child is now exposed to the repeating patterns of the speaking voice. The emphasis is put onto the speech melody and rhythm. The sounds of the voice are underlined prior to words, yet each sound has a function, becoming a formant of a phoneme, a phoneme, and then a word. The process of crystallizing the functions of the word and then the word is aligned with the moment of distinguishing the speaking voice. In the last phase, the child repeats the word, and hears his own voice back with the headphone.

The procedure of semiophony suggests the exact opposite of Lucier's I am sitting in a room. The therapy attempts to cure a kind of verbal deafness by means of solidifying the speaking voice and the word. Lucier's piece in contrast tends to erase such solidification. Instead it liquidates the voice and the word, and leads us to the experience of the sound bath, the "sound space," which indicates a mingling of external and internal noises that we cannot perfectly locate or of which we are not completely cognizant, and which are "accompanied by an active motor image, and all contribute to forming a space" ${ }^{36}$ in Anzieu's words. In other words, sound space can be considered a flux of the residues of the echo, which are lost in the embodied absence of sound, that is we feel the touch of sound, yet cannot perfectly locate it, and in the imagined presence of sound, that is we contextualize the sound yet cannot perfectly grasp it. Lucier employs speech sounds as a zone to explore these capacities of sound space:

... I decided to use speech; it's common to just about everybody and is a marvelous sound source. It has a reasonable frequency spectrum, noise, stops and starts, different dynamic levels, complex shapes. It's ideal for testing the resonant characteristics of a space because it puts so much in all at one time. It's extremely personal...you know I'm a stutter. So instead of trying to invent interesting speech patterns, I discovered that I have interesting speech patterns anyway; I don't have to invent them ... ${ }^{37}$

Lucier treats speech-and more importantly his stutter, the irregularity of his speech-as a key to measure the shapes and dynamic levels of both sound and space. He considers this a resource for understanding the personal body of sound. Repeating the speech patterns and allowing them to be gradually transformed into one another, he follows the founder of psychophysics, Gustav Fechner's method on measuring sensation: repetition. As Fechner posits, understanding the degree of intensity is

\footnotetext{
35 Ibid.

${ }^{36}$ Ibid., 170 .

${ }^{37}$ Douglas Simon, “Interviews with Douglas Simon" in Alvin Lucier: Reflections, Interviews, Scores, Writings (Cologne: Edition Musik Texte, 1995), 98.
} 
possible via repetition of the same event, be it mental or/and physical.

In his analysis, Fechner first looks at skin. We can count the repetitive occurrences on our external skin, yet how are we able to count the occurrences that happen below the skin? In other words, how do we measure the sensitivity of the skin? Fechner offers two parameters: spatial magnitude and sensory circles. Moving from these two parameters, Fechner divides sensitivity into two categories: extensive (sensory circles on skin, for instance, yet Fechner also criticizes treating these circles as quantitative) and intensive (unknown magnitude, may be spatial, of psychophysical processes). However, Fechner suggests these categories not to assure that the former is distinctively measurable as opposed to the latter, but to make us aware of the fact that both are referential to each other:

It must be admitted that measured data of the extensive sensitivity, as well as those of the intensive have only the value of observational data, which by themselves do not provide insight into the basic relationships of sensation to their physical basis, but which, together with other data, may yet serve to contribute to the establishment of this relationship... ${ }^{38}$

Therefore, sensitivity is a variable dependent on both psychic and physical state, and both are measurable to the same degree. Following this assertion, Fechner argues that there cannot be a constant to measure sensitivity. Instead of a constant, Fechner looks at the "conditions" that determine the nature of sensation and the "mean values" of the repeating occurrences that lead to more or less the same sensation. ${ }^{39}$ This presumes that we can treat each sensation as a summable unit. Fechner explicitly states that as such: "in principle our psychic measurement will amount to the same as physical measurement, the summation of so-and-so many multiples of an equal unit." ${ }^{20}$ After the point of saturation, however, we might not be able to recognize, count or sum the units. What happens after that point? Fechner's answer to that question is that once we stop counting, we start to fulfill the habit of counting with something else: psychic stimuli. The striking example that he gives is time and space:

After all, do we count periods of time, when measuring time, or spatial units directly in terms of space, when we measure space? Do we not rather employ an independent yardstick, a measuring rod, which for time does not consist of pure time, nor for space of pure space and for matter of pure matter alone? Measuring any of these three quantities demands something else as well. Why should the case not be the same in the mental and psychological sphere? ${ }^{41}$

Fechner's question indeed reasserts the fact that there is no pure time, space or matter. Similarly, measurement of intensity cannot be precise. Take pain. How does one measure pain? In hospitals, for instance, indicative bands are used to identify degrees of pain. When asked about the precise location of pain, or where exactly it hurts, we usually tend to detect or point an area that relates to the feel of pain. Both in Difference and Repetition and in the Logic of Sense, ${ }^{42}$ Deleuze reminds the differences in kind and degrees, that is the differentials, which lead to multiplicities. Intensity is related to such logic, to structuring and unfolding of zones through differentials, through the "non-countable." ${ }^{43}$ The point of the

\footnotetext{
${ }^{38}$ Gustav Theodor Fechner, Elements of Psychophysics, translated by E. Adler, edited by David H. Howes and Edwin G. Boring, with a new introduction by Edwin G. Boring (New York: Holt, Rinehart, Winston, 1966), 44.

${ }^{39}$ Ibid., 45.

${ }^{40}$ Ibid., 47.

${ }^{41}$ Ibid.

${ }^{42}$ Gilles Deleuze, The Logic of Sense, translated by Mark Lester with Charles Stivale, edited by Constantin V. Boundas (New York: Columbia University Press, 1993); Difference and Repetition, translated by Paul R. Patton, (London: The Athlone Press, 1994).

${ }^{43}$ It would be worthwhile to note that the "non-countable" here refers to Deleuze and Guattari's notions of "nonsense" and "body without organs". The notion of body without organs owes its inspiration to Antonin Artaud's schizophrenic speech,
} 
non-countable is the point when we are "outside of time, narrative, meaningful sequencing." 44 The point of the non-countable pronounces a space that is both extended and expanded by vibration.

There is constant vibration in and around us; yet the sociality of vibration, the question of cosounding-of how we give a form to vibration, and in what forms and conditions we share vibration-is contested. Articulating speech and space through vibration, I am sitting in a room amplifies the question of co-sounding. Its multi-sensory modality, vocal split, spatial spread and sonic continuum contest the order of language. Unfolding itself as vibration, it turns the physical environment itself into a voice, one that cannot be easily categorized. In her book, Senses of Vibration, Shelley Trower discusses how in contemporary theory vibration is conceptualized as "resistance to boundaries and identities" and how such conceptualization is both feeding into and being fed by the "history of the material imagination":

Vibration commonly provides a means of conceptualizing resistance to boundaries and identities in contemporary theory, which we might begin to trace back to the eighteenth and nineteenth centuries. Vibrations are becomings that undermine stable forms and identities,' notes David Bissell, following Gilles Deleuze and Felix Guattari. For Jean Luc Nancy, 'the sonorous [...] outweighs form. It does not dissolve it but rather enlarges it; it gives it an amplitude, a density and a vibration or an undulation whose outline never does anything but approach. For Latour, vibration provides a model for 'entities with certain boundaries, entities that hesitate, quake, and induce perplexity.' Vibration, not itself a thing or matter, can move simultaneously through subjects as well as objects, bridging internal and external worlds. Indeed, vibration was key to the increasing understanding that mind itself is material, as Enlightenment thinkers had begun to shift attention from the transcendent soul to the mechanics of physical form ... Vibration plays a part in the history of the 'material imagination",45

In line with this conceptual trajectory of vibration, consider resonance. Veit Erlmann's noted book, Reason and Resonance, discusses contingent definitions of resonance, situated between history of science and history of ideas, as well as between art, literature and music. Following the idea of material imagination, the $19^{\text {th }}$ century scientific reasoning and aesthetics accommodates a resonance, one that can be heard in dissonance, in the multitude of heightened vibration. In relation to this resonance, or reasonance, in Erlmann's words, I wish to draw attention to two themes that Erlmann underlines: "sonic excess" and "sonic reflexivity." I consider these themes informative and suggestive for understanding the decompression of Lucier's text and speech into a space of heightened vibration, and for what follows in the next section, the cross reading I propose between the aestheticized and the pathologized speech.

Erlmann indicates sonic excess and sonic reflexivity in his discussion on the correspondence between poet Wilhelm Heinse and scientist Samuel Thomas Sömmering. The correspondence between Heinse and Sömmering oscillates between the poetry and wonder of "water" and the physiology of the

\footnotetext{
where excessive fragmentation in verbal expression becomes nonsense, unidentifiable noise. Gilles Deleuze and Felix Guattari, A Thousand Plateaus: Capitalism and Schizophrenia, translated by Brian Massumi (Minneapolis: University of Minnesota Press, 1987).

${ }^{44}$ Here I refer to Brian Massumi's account of intensity: "Intensity is not semantically or semiotically ordered. It is outside expectation and adaptation, as disconnected from meaningful sequencing, from narration, as it is from vital function. It is narratively de-localized, spreading over the generalized body surface, like a lateral backwash from the function-meaning interloops traveling the vertical path between head and heart. Language, though head-strong, is not simply in opposition to intensity. It would seem to function differentially in relation to it." Brian Massumi, "The Autonomy of Affect," Parables for the Virtual: Movement, Sensation, Affect (Durham: Duke University Press, 2002), 24-25.

${ }^{45}$ Shelley Trower, Senses of Vibration: A History of the Pain and Pleasure of Sound (New York: Continuum, 2012), 8-9. Also, see musicologist Nina Sun-Eidsheim's recent book, Sensing Sound: Singing and Listening as Vibrational Practice (Durham: Duke University, 2015).
} 
"ear." All begins with the water, as Heinse proposes. Heinse draws a connection between water and sound's "oceanic feeling of holiness," which leads to a "numbing of senses," 46 to a translation of surplus of sound into loss of sense and self. Likewise, Sömmering draws a connection between the water and sound; yet more specifically, he tests the parallel between the water and the liquid inside of the ear and articulates the direct contact between the "moistness of the brain cavities" and the "auditory nerve." 47 Despite the $17^{\text {th }}$ and $18^{\text {th }}$ century discourse on hearing and sound, which qualified the physiology of hearing as antimechanistic, unlocatable, and elusive, Sömmering argued that hearing is "our most exact sense." According to Sömmering, ear was the organ, which brings all senses together, which sharpens each one of them as distinct, and which generates a "conscious mind" and a "self-reflexive subject." account of hearing is still a viable issue, as also raised by Erlmann. This theory of hearing-what Erlmann also calls "transcendental physiology" - respectively influenced the organicism in philosophy of nature and aesthetics. ${ }^{50}$

One may contest Erlmann's notion of “transcendental physiology” here. Sömmering considers hearing an organic media of all senses, yet he does not delete the sensory boundaries or the conscious perception of each individual sense. The "self-reflexive" subject is not immersed in self-doubt. In other words, the perceiving subject does not fully disappear within the process of hearing. The twisted naming of transcendental physiology perhaps anchors Heinse's appropriation of Sömmering's theory. In light of this theory, Heinse reflects on the mythologies, mania of sensory abundance and immersion, and on the "erotics" of listening and water. Erlmann points at Heinse's "erotics of listening" as it informs the era's other conceptual landmarks inherited from the Enlightenment: "noise, euphoria, sublime and vertigo." For this sensory abundance, Heinse's inspiration was mostly Gluck's operas. When he associated music with ocean, vast and deep water, he mostly referred to the sounds of the voice. ${ }^{52}$ As Erlmann explains, Heinse was particularly interested in speech physiology, and influenced by Denise Dodart's Sur les causes de la voix de l'homme $\mathcal{E}$ de ses differens tons. ${ }^{53}$

The theories on speech crystallized and reinforced the conception of Romantic listening and aurality in the service of the "self-reflexive subject," of "auto-affection." The term, auto-affection, was much later pronounced and triumphed by Derrida. Erlmann's remarks on auto-affection provides a key not only for Heinse's conception of aurality but also for the Romantic aurality and its link to modern subjectivity:

Heinse appropriated for himself Dodart's and Ferrein's findings on the voice as an instrument of "autoaffection." It was in 1791 that Wolfgang von Kempelen had published a lengthy description of a device he called a speaking machine ... von Kempelen's machine is a

\footnotetext{
${ }^{46}$ Veit Erlmann, Reason and Resonance: A History of Modern Aurality (New York: Zone Books, 2010), 151-52.

${ }^{47}$ Ibid., 152.

${ }^{48}$ Ibid., Sömmering's primary reference was the "liquid inside the labyrinth of the ear" which was discovered by Domenico Cotugno in 1760. Ibid., 153, 155.

${ }^{49}$ Erlmann mentions Sömmering's dedication to Kant. Nevertheless, in his Critique of Pure Reason, Kant criticizes Sömmering's take on the "self-reflexive subject" and soul, which comes with the ear. For Kant, the distinction between the internal and external and the body and soul was sharp. Erlmann quotes: "Now while the soul can perceive itself only through the internal sense, it can perceive the body only through the exterior senses. Thus it cannot determine for itself a location, because for that it would have to turn itself into an object of its own external apperception and externalize itself outside of itself-which contradicts itself.” Ibid., 156, 158, 157.

${ }^{50}$ Ibid., 159-160.

${ }^{51}$ Ibid., 165-166.

52 See 169, 170.

${ }^{53}$ Erlmann explains: "On the causes of the Human Voice and Its Different Sounds" showed that the vibrating lips of the glottis produces the phonation. Later, Antoine Ferrein conducted an empirical research on dogs and deceased prisoners and concluded that phonation was generated by the tension of the vocal cords. Ibid., 175, 176.
} 
quintessential example of the technological a priori of Derrida's phonocentric 'hearingoneself-speak' and an illustration of the precarious position of early Romantic aurality as one of the major touchstones of modern subjectivity. ${ }^{54}$

Erlmann couples auto-affection, "hearing oneself speak," with "hearing oneself hear," the "auto-resonant self." In doing so, he maps on the connections between voice and auditory perception, auditory imagination, listening, consciousness and subjectivity. The "sonic excess" and "sonic reflexivity" 55 is situated in this web. The former implies a "bodily immersion" through which the ego is lost. The latter suggests a "self-reflexive subject" which does not allow a complete loss of the ego. As Erlmann argues, these two aspects as necessary components of the "auto-resonant listener." ${ }^{\text {"I }}$ I suggest these concepts as significant aspects for what follows next, the sonorous plane, the sonorous walls, and sonorous bits.

\section{Sonorous planes, sonorous walls, sonorous bits}

French psychiatrist, musician and music therapist Edith Lecourt expands on Anzieu's theory of sound envelope and uses a new term, musical envelope, to establish a therapeutic treatment. Lecourt characterizes "sonority' with "absence of concreteness or boundaries." ${ }^{27}$ If the physical aspects of sound imply a flux, how are we able to draw where sound begins and ends? Thus, her analysis necessarily complicates the concept of envelope. The notion of envelope indicates containment and limit and requires an inter-sensory continuum. An inter-sensory continuum, sound not simply contains but also extends. Following this line of thought, Lecourt qualifies the sonorous bath as "a relationship or surface to volume" and "the experience of weightlessness, and of being carried; the function of surrounding." "The experience of sonorous bath is related to touch, smell, taste and vision. In that respect, Lecourt brings the notion of "oral cavity" back. This reassures grasping the sonorous experience as a global one. The sonorous envelope embodies the potential not only for a "verbal face" but also for a "musical face" terms. Unlike sound, both verbal and musical faces seem to indicate the existence of a text, a particular grammar and content. Nevertheless, Lecourt differentiates the two as such:

The verbal face more linear (in time), univocal and a visible thread in the texture, is turned towards the outside. The musical face, in thickness, woven of voices (in space as in time), and plurivocal, is turned more towards the inside. Their modes of contact are very different: one sounds, sings, vibrates and resonates-as in the sonorous bath-the other is articulatory and more abstract ... ${ }^{60}$

The way Lecourt differentiates music from verbal language is similar to the distinction between the first and secondary articulation of language that has already been raised by Anzieu previously. Lecourt contributes to this picture with her specific examples from contemporary music such as John Cage, Pierre Henry, Karlheinz Stockhausen, Gerald Grisey, Luciano Berio and Vinko Globokar. Briefly looking at these examples, she indicates the role of contemporary classical music in incorporating everyday noises and speech sounds into music and in decomposing musical elements into sound events. The aesthetic of

\footnotetext{
${ }^{54}$ Ibid., 177, 280.

${ }^{55}$ Ibid., 187.

${ }^{56}$ Ibid., 188.

${ }^{57}$ Edith Lecourt, "The Musical Envelope," in Didier Anzieu’s Psychic Envelopes, trans. Daphne Briggs (London: Karnac Books, 1990), 211.

${ }^{58}$ Ibid., 214.

${ }^{59}$ Ibid., 225.

${ }^{60}$ Ibid.
} 
contemporary music resonates with the foundation of sound envelope. Three aspects-repetition, dissolution and continuous flux of sound-of this aesthetic lead Lecourt to question the "limits of intensity, or of sonorous volume."

Lecourt uses the "musical envelope" as a form of treatment. She looks at two cases: David's case of autism and verbal deafness and Paul's case of psychic deafness. Paul can only hear speech but nothing else, ${ }^{62}$ whereas David cannot hear words as he has hyper excitation and sensitivity regarding sound, which leads him to be almost always in a trance state and become a "verbal deaf." Verbal deafness, "auditory verbal agnosia," is defined as the "failure to recognize linguistic stimuli." Psychic deafness, auditory agnosia for nonlinguistic sounds, is on the other hand explained "as the failure to recognize or distinguish various sounds." ${ }^{63}$ In both cases, hearing is not necessarily impaired. However, neurolinguistic investigations speculate about the impact of phonetic and auditory dysfunctions on speech perception. ${ }^{64}$

For David's verbal deafness, Lecourt “differentiates" and "neutralizes” David's sensory excitation by channeling and accommodating the repetition of his actions. "David used repetition to attempt precisely to grasp something," she writes. ${ }^{65}$ Imagine David's global excitation as a sound bath, within which sounds are in constant flux and not perfectly locatable for him. Only visual repetition helps him weigh the sounds and turn them into patterns of words. Paul on the other hand is threatened by the weightlessness of sound. As opposed to David, he can only pick up verbal patterns:

... a very heavy narcissistic pathology, presenting as psychic deafness to all noise and all music, but not to speech. At fifteen years of age, Paul literally "woke up" to the sonorous world, to the extent of taking a real pleasure in it. This leads us to the concept of "sonorous wall" proposed by R. Gori (1978), which seems to me to be the counterpart on the sonorous plane of the cuirass on the tactile lane: "the overflow of signs or over flow sounds construct a false skin, a sonorous culvert, a pneumatic cushion, which-like walls-protect the self from communication that is perceived as an intrusion threatening the boundaries of the ego." Here I see two aspects of the pathologies encountered: total obstruction on the one hand, and the reverberant surface on the other ... ${ }^{66}$

Imagining the words with the metaphor of the wall can be protective for Paul, helping him isolate himself from the rest of the world. Plane, on the other hand, is horizontal, bringing infinite and contingent possibilities, perhaps diminishing Paul's feel of self-control over the external things.

Both the sonorous wall and the sonorous plane wrestle with fragmentation-bits_of language.

\footnotetext{
${ }^{61}$ Ibid. 228.

${ }^{62}$ Ibid., 229.

${ }^{63}$ Ibid., 226. Bruce E. Murdoch explains auditory agnosia: "In this condition, although hearing is not impaired, the patient is unable to recognize or distinguish various sounds. For instance, provided no visual or tactile stimuli are provided, the patient cannot recognize familiar noises, such as the jingling of coins or keys. In some cases, this inability may also extend to speech. Two different types of auditory agnosia which may occur independent of one another are currently recognized, First an auditory agnosia for non-linguistic sounds (also called psychic deafness) has been described which involves an inability to recognize non-linguistic auditory stimuli such as animal noises, bells ringing and so on. Second, in some cases the auditory agnosia may selectively involve a failure to recognize linguistic stimuli. This latter condition has been referred to as "auditory verbal agnosia" or pure word deafness (subcortical word deafness). Pure word deafness is a rare disorder in which, although patients cannot repeat words or write to dictation, their spontaneous speech, writing and reading abilities are not disrupted. Although it is somewhat controversial, auditory agnosia for non-linguistic stimuli is thought to be caused by lesions which involve the auditory association cortex of both hemispheres but which spare Heschl's gyrus ... In auditory agnosia, the affected individual is unable to recognize or distinguish various sounds, even though their hearing is not impaired." Bruce E. Murdoch, Acquired Speech and Language Disorders (London: Wiley-Blackwell, 2010), $240-241$.

${ }^{64}$ See Peter Praamstra, Peter Hagoort, Ben Maassen and Thom Crul, "Word Deafness and Auditory Cortical Function: A Case History and Hypothesis," Brain 114 (1991): 1197-1225.

${ }^{65}$ Lecourt, The Musical Envelope, 227.

${ }^{66}$ Ibid., 229.
} 
They encourage us to consider different forms of relating to sound, voice and speech. It would be useful to note that the sonorous wall and plane are not therapeutic methods or diagnostic tools to rehabilitate verbal or auditory agnosia. The sonorous wall and plane are different neurological conditions of experiencing and embodying concrete sounds, voice and language. Lecourt's article demonstrates these conditions exemplifying David and Paul's cases. I do not refer to these cases as a metaphor for understanding what's at stake in I am sitting in a room. Rather, I wish to underline the emergence of a similar experience of the sonorous wall and plane in the piece. Lucier consider his piece a way to "smoothen" his speech irregularity. That is, one could consider the decompression-as well as the compression of the voice with tape recording_of Lucier's voice and speech a therapy for stutter. My suggestion here is to look at how Lucier's speech irregularity functions as a moment of vocal split yet gives a way to sonic continuum, neither as speech pathology nor as a functional treatment.

Given the ways in which the text is dissolved and the voice is distributed in space, and the literality between the text and the performance of the text, I am sitting in a room provides us with the affective capacity to turn one's body on the one hand into a "total obstruction," and on the other hand, into a "reverberant surface" of the external world. The piece allows a space to be engaged in the embodiment of sound, in the ways in which the constituents of a voice and speech unfold and emerge across the planes, walls, and bits of sound. It thus heals the stutter-restores its split into a sonic and sensory continuum-as it re-defines the stuttering voice at the heart of this relation, of what Erin Manning terms, "body-worlding, a suprasociality, a relationality activated at the very internal of relation itself." 67

\section{Bibliography}

Anzieu, Didier. The Skin-Ego. New Haven, CT: Yale University Press, 1989.

Bachelard, Gaston. Air and Dreams: An Essay on the Imagination of Movement. Translated by Edith R.Farrell and C. Frederick Farrell. Dallas, TX: The Dallas Institute of Humanities and Culture Publications, 1988.

Bion. W.R. "Language and the schizophrenic." In New directions in psycho-analysis: the significance of infant conflict in the pattern of adult behaviour. Edited by Melanie Klein, Paula Heimann, and R. E. MoneyKyrle with a preface by Ernest Jones. New York: Basic Books, 1957.

Bulut, Zeynep. "La Voix-Peau: Understanding the Physical, Phenomenal and Imaginary Limits of the Human Voice Through Contemporary Music.” PhD diss., University of California at San Diego, 2011.

Connor, Steven. "The Decomposing Voice of Postmodern Music," New Literary History 32 (Summer 2001): 467-83. http://dx.doi.org/10.1353/nlh.2001.0031.

—_. "St...st...st," Beyond Words: Sobs, Hums, Stutters and other Vocalizations. London: Reaktion Books, 2014.

—_. "Phonophobia: The Dumb Devil of Stammering," http://www.stevenconnor.com/phonophobia/.

Curlee, Richard. "Stuttering," in The MIT Encyclopedia of Communication Disorders, Ed. Raymond D. Kent, Massachusetts: MIT Press, 2004, 220.

${ }^{67}$ Erin Manning introduces these terms in her discussion on American autism activist Amelia Bagg's video, In My Language. Manning, Always More Than One, 8-10. 
Deleuze, Gilles and Felix Guattari. A Thousand Plateaus: Capitalism and Schizophrenia. Translated by Brian Massumi, Minneapolis: University of Minnesota Press, 1987.

Deleuze, Gilles. The Logic of Sense. Translated by Mark Lester with Charles Stivale, edited by Constantin V. Boundas, New York: Columbia University Press, 1993.

- Difference and Repetition. Translated by Paul R. Patton. London: The Athlone Press, 1994.

Eagle, Christopher. Talking Normal: Literature, Speech Disorders, and Disability. Edited by Christopher Eagle, New York: Routledge, 2014.

Eidsheim, Nina Sun. Sensing Sound: Singing and Listening as Vibrational Practice. Durham, NC: Duke University Press, 2015. http://dx.doi.org/10.1215/9780822374695.

Erlmann, Veit. Reason and Resonance: A History of Modern Aurality. New York: Zone Books, 2010.

Fechner, Gustav Theodor. Elements of Psychophysics, translated by E.Adler, edited by David H. Howes and Edwin G. Boring, with a new introduction by Edwin G. Boring. New York: Holt, Rinehart, Winston, 1966.

Goldstein, Kurt. Language Disturbances: Aphasic symptom complexes and their significance for medicine and theory of language. New York: Grune \& Stratton, 1948.

Kim-Cohen, Seth. In the Blink of an Ear: Toward a Non-Cochlear Sonic Art. London, New York: Bloomsbury, 2009.

Kreiman, Jody and Diana Sidtis. Foundations of Voice Studies: An Interdisciplinary Approach to Voice Production and Perception. West Sussex, UK: Wiley-Blackwell, 2011. http://dx.doi.org/10.1002/9781444395068.

LaBelle, Brandon. Background Noise: Perspectives on Sound Art. London, New York: Continuum, 2006/2010.

Lagaay, Alice. "Between Sound and Silence: Voice in the History of Psychoanalysis," E-pisteme, 1 (2008): 54-62.

Lecourt, Edith. “The Musical Envelope," in Didier Anzieu's Psychic Envelopes, edited by Didier Anzieu, translated by Daphne Briggs (London: Karnac Books, 1990), 213-35.

Lucier, Alvin. I am sitting in a room, New York: Lovely Music, 1990.

Malabou, Catherine. "Plasticity and Elasticity in Freud's Beyond the Pleasure Principle," Diacritics 37(Winter 2007): 78-85. http://dx.doi.org/10.1353/dia.0.0038.

Manning, Erin. “Towards a Leaky Sense of Self,” in Always More Than One: Individuation's Dance. Durham, NC: Duke University Press, 2013.

Massumi, Brian. Parables for the Virtual: Movement, Sensation, Affect. Durham: Duke University Press, 2002. http://dx.doi.org/10.1215/9780822383574.

McKenna Peter J. and Tomasina M.Oh. Schizophrenic Speech: making sense of bathroots and ponds that fall in doorways. Cambridge, New York: Cambridge University Press, 2005.

Murdoch, E. Bruce. Acquired Speech and Language Disorders, London: Wiley-Blackwell, 2010.

Potter, Samuel. Speech and its Defects. Philadelphia, PA: P. Blakiston, Son \& Co., 1882.

Praamstra, Peter, Peter Hagoort, Ben Maassen and Thom Crul. "Word Deafness and Auditory Cortical Function: A Case History and Hypothesis," Brain 114 (1991): 1197-225. http://dx.doi.org/10.1093/brain/114.3.1197.

Scripture, Edward Wheeler. Stuttering and Lisping. NY: The Macmillan Co., 1912.

Simon, Douglas. "Interviews with Douglas Simon" in Alvin Lucier: Reflections, Interviews, Scores, Writings, Cologne: Edition Musik Texte, 1995. 
Stern, Daniel N. Forms of Vitality: Exploring Dynamic Experience in Psychology, the Arts, Psychotherapy, and Development. Oxford: Oxford University Press, 2010. http://dx.doi.org/10.1093/med:psych/9780199586066.001.0001.

Sterne, Jonathan. The Audible Past: Cultural Origins of Sound Reproduction. Durham: Duke University Press, 2003. http://dx.doi.org/10.1215/9780822384250.

Trower, Shelley. Senses of Vibration: A History of the Pain and Pleasure of Sound. New York: Continuum, 2012.

Van Riper, Charles. Speech Correction: Principles and Methods. New York: Prentice-Hall Inc., 1939.

Weiss, Allen. Breathless: Sound Recording, Disembodiment, and the Transformation of Lyrical Nostalgia. Wesleyan: Wesleyan University Press, 2002.

\begin{abstract}
This article discusses how the non-linguistic voice in avant-garde and experimental music can unsettle and expand on the normative limits of the knowledge of the voice, language and speech. Drawing on Alvin Lucier's I am sitting in a room, and on cases of stuttering, verbal and psychic deafness, I address the following questions: How can the embodied sound of the voice be deployed as a performative tool to challenge and "heal" speech irregularity? And what do "speech irregularity" and "healing" mean in this context?
\end{abstract}

